\title{
ISPRS STUDENT CONSORTIUM: THE NETWORK OF YOUTH IN GEOINFORMATION SOCIETY
}

\author{
C. O. Kivilcim ${ }^{\mathrm{a}, *}$, K. Sterenczak ${ }^{\mathrm{b}}$, U. Kanjir ${ }^{\mathrm{c}}$, A. Sengul ${ }^{\mathrm{a}}$, \\ G.Stavbar ${ }^{c}$, M.E.Pakdil ${ }^{a}$, E. Lobo ${ }^{\mathrm{d}}$, K. S. Oo ${ }^{\mathrm{e}}$ \\ ${ }^{\text {a }}$ ITU, Department of Geomatic Engineering, Civil Engineering Faculty, Istanbul Technical University, Turkey; \\ ${ }^{\mathrm{b}}$ Department of Forest Management, Geomatics and Economics, Faculty of Forestry, Warsaw University of Life \\ Sciences, Poland; \\ ${ }^{\mathrm{c}}$ Faculty of Civil and Geodetic Engineering, University of Ljubljana, Slovenia \\ ${ }^{\mathrm{d}}$ Smithsonian Tropical Research Institute, Panama \\ e Takagi Laboratory, Kochi University of Technology, Japan \\ kcemalozgur@hotmail.com, krzysztof.sterenczak@wl.sggw.pl, ursa.kanjir@gmail.com, ahmetsengul@gmail.com, \\ mete@mtrcn.com, elobo2@life.uiuc.edu,kyawsannoo@yahoo.com
}

Commission VI, WG VI/5

KEY WORDS: Education, Training, Sustainable Society, Organization, Future, ISPRS Student Consortium

\begin{abstract}
:
The ISPRS Student Consortium (SC) initiative started at the 20th ISPRS Congress in Istanbul, 2004.After four years of volunteer activity, an official structure for volunteers was needed. With the implementation of the SC Statutes in the ISPRS Beijing Congress in 2008, the first ISPRS Student Consortium Board Members were elected. Since this day, SC volunteers and supporters have continued to contribute through numerous activities in order to promote the Society and connect young people with a similar interest in the profession. So far, promotional activities have taken place in various places in Europe, North and Central America, Asia and Australia. SC members have not only participated in the events, but also organized activities, taken responsibilities and represented youth in ISPRS midterm symposiums and ISPRS Centenary Celebrations as well as other related events. Summer schools, as the main SC event, are organized with the help of ISPRS TC VI/5 and are focused on the needs and interests of scientific communities around the world. The SC community has been constantly growing with almost 750 members over 85 countries at present, registered through our self-developed website. The organization also publishes its own Newsletter four times per year, with the intention to transmit the messages and news from ISPRS and the SC. The Newsletter is a perfect platform for presenting useful technical, educational and informational material prepared by members and distributed freely among the supporters. Throughout time, the SC has received guiding, motivational and administrative support from WG VI/5 as well as TC VI and the ISPRS Council. Activities have been financially supported by foundations, commercial enterprises and academic organizations and many SC members have received grants to present their work in different scientific events. In addition, the SC has started and established permanent connections and signed agreements for better networking with the youth organizations of the sister Societies of ISPRS. This paper presents the achievements reached over the last four years, the experiences of the SC Board and Regional Representatives and the feedback from our members. It provides an insight for the youth organizations run under other scientific and technical societies. A vision for the continuum of the activities and establishing regional and national developments are suggested. A revised road-map for the future is outlined in the conclusion.
\end{abstract}

\footnotetext{
* Corresponding author.
} 


\section{INTRODUCTION}

This paper presents a full overview of the ISPRS Student Consortium (SC). The paper starts with a section in which we explain the need for a network of young individuals as part of a Society in the field of Geo-Information, which is ISPRS. The following sections go through a historical background and progress towards the present of the SC. Then, we analyze the resources provided by the SC to its members, including the SC Newsletter, the SC web capabilities and the network of regional coordinators. The following section describes the activities in which the SC has been involved, including participation and promotion in regional events, SC Summer Schools and international events.

The paper continues by analyzing the results of a SC member survey, which covers the main aspects of the process by which young individuals are integrated into ISPRS. Through the survey, completed by a total of 125 respondents, we are able to obtain valuable feedback from our members, which we can use to define the key goals and objectives for the continuation and improvement of the SC. These goals start with improving the activities designed to attract young individuals, followed by supporting events that provide critical opportunities for young academicians and professionals to develop their careers. At the end of the paper, we summarize the experiences gathered in the last decade and we define the road-map for the future of the SC.

\subsection{Motivation for a Youth Network}

Students and young professionals at the beginning of their careers seek advice and need guidelines to address their future. Young individuals look for groups where they can find information and answers and share their experiences for improving their education and developing a successful career. On the other hand, the long-term sustainability of any organization is based on the continuous integration of the new generations. Consequently, the efforts and actions aimed at attracting new fellows are a key component for the development of ISPRS. As a consequence of this unfulfilled need for the youth of the profession, a significant decrease of contributions from youth was reported to ISPRS and ISPRS-supported activities. ISPRS' approach to solve this problem was creating a strategy involving all the necessary steps to welcome young individuals to become an official part of the society.

\subsection{Background}

Emmanuel Baltsavias reports that it was during ISPRS Congress Vienna in 1996, the Best Papers by Young Authors Awards were given for the first time. (Baltsavias, 2005). However, it took years to come up with the materialization of the Youth, with sessions dedicated only to youth. A group of students addressed Prof. Dr. Orhan Altan, who was in charge as the Director of Istanbul Congress at that time, with the request to organize a youth forum in order to encourage young individuals to participate at the ISPRS Congress in 2004. The Istanbul Congress offered more to youth: an international youth forum was organized and a summer camp for the students and young professionals was held near the ancient city of Troy; both events were organized by young professionals and students. That was the first time in the history of ISPRS that such activities took place during a scientific congress. Furthermore, during the closure of the youth forum, a podium discussion was held by students to evaluate the activities. In this session, the idea to organize a youth forum as part of the next ISPRS congress was presented. Additionally, the need of a concrete official structure to represent and integrate the young individuals into ISPRS was emphasized. The conclusions reached through these discussions were supported by the Council of 2004-2008 and the ISPRS Student Consortium was born. The successful student activities and Youth Forum sessions in Istanbul played an important role in the establishment of the ISPRS SC. Officially; the ISPRS Student Consortium (SC) was founded under the Commission VI /WG 5 with the motto "Promotion of Profession to Students". A group of students mostly from Europe, who had organized the student activities in the Istanbul Congress, were appointed as the student coordinators and initialized the first steps of the SC (Akkoca et. al., 2005; Kivilcim, 2008).

One year after the ISPRS Congress, the first major activity of the ISPRS SC took place; this was the 1 st International Summer School, held in Istanbul in 2005. After this summer school, major coordinators and local students who were involved in the organization of the summer school continued their activities with different timelines. However, with the change of the working group chair and some of the SC coordinators, the first members became less active during the first two years of the organization.

After the 2nd Summer School in Slovenia in the year 2007, thanks to the initiatives of the new WG VI/5 Chair, the TC and the ISPRS Council, a new team of students from local groups and existing members filled the positions of the ISPRS SC. The problems that had been experienced were analyzed by Fras and Lisec, as the Working Group VI/5 Officers, and consequently an organization scheme for efficient communication and structuring the workflow among the SC volunteers was presented (Fras and Lisec, 2008).

In the Beijing Congressin 2008, the annual Student Consortium Summer School was held as a pre-Congress event in Nanjing. During the Congress, the Youth Forum, with more than 90 submitted abstracts and four technical sessions, took place as well as a poster session (Molenaar, 2008). Aside from the technical program, a panel session on soft-skill development was held in cooperation with the White Elephants team. Finally, the ISPRS SC General Assembly was held for the evaluation of the SC and planning of the future. A trip to the Chinese Great Wall as a part of the Youth Forum was organized and informal social meetings were held among young congress participants. Figure 1 shows the participation at one of the Youth Forum activities: the White Elephants Session.

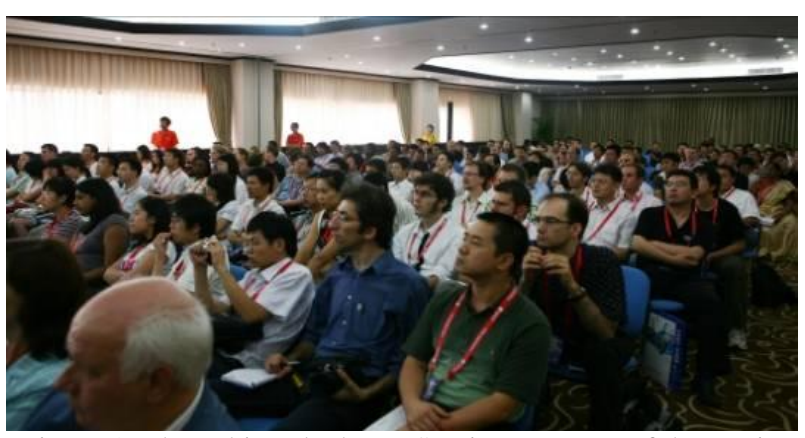

Figure 1. The White Elephants Session as a part of the YF in Beijing Congress.

In addition to these efforts, the need to define the roles and responsibilities of individuals volunteering brought to light the necessity of official regulations and documentation. A Statute was created stating the mission and activity areas as well as the 
roles of an executive board of elected individuals. Candidates for the several roles were presented and voted by the General Assembly formed during the Youth Forum in the Beijing Congress. With the overall acceptance of these guidelines, the first Student Consortium Board members were voted and elected. Subsequently, the adapted statutes and SC-elected Board were approved by the ISPRS Council. Figure 2 shows the group picture of the ISRPS Council Members, TC VI and WG officers, and the newly elected SC Board Members and local members of YF organizers.

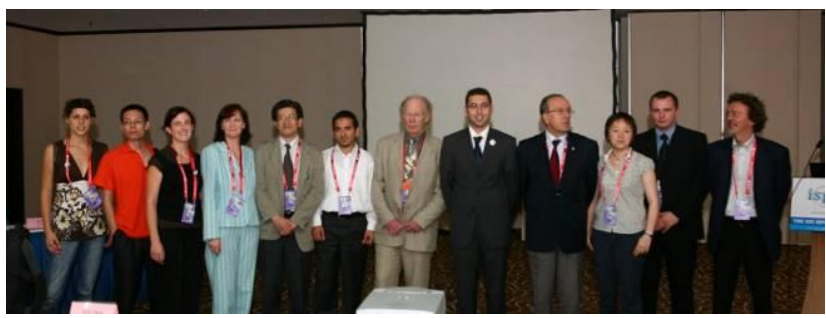

Figure 2. Group picture at the closing of the Youth Forum in Beijing 2008.

The SC established during the XXth ISPRS Congress Istanbul in the year of 2004, reached its first milestone in 2008 with the XXIst Beijing Congress. With the accepted SC statutes in Beijing, the SC re-shaped into a new structure in the period 2008-2012. (Kivilcim, et. al. 2010)

\section{PROGRESS AND ACHIVEMENTS DURING 2008-2012}

In the first months after the Beijing Congress in 2008, the initial key issues were addressed by the SC Board and TC VI/5: Standard promotional materials; poster and leaflet designs were updated and a well-structured online database and announcement system were created and activated. All this was accomplished based on the ideas, work and efforts of the SC Board and active members. The primary network and the backbone of the Global communication were materialized via the Internet. The Student Consortium Board, Regional Members, ISPRS WG VI/5 Chair and SC Liaison in the Council maintained hundreds of e-mail discussions to define and reach these first objectives. During the year 2008, several teleconferences and video-call meetings also took place between the members of the SC Board. The SC made a headstart in the goals for the term. However, starting on late 2008, various activities and challenges were faced in the organization. SC volunteers needed to sacrifice a huge amount of time and effort conducting volunteer activities in order to sustain the network. In the following section, the different kinds of services, their evolution along the term and various other activities are presented.

\subsection{Events and Activities during the 2008-2012 term}

\subsubsection{Newsletter}

The first issue of the Student Consortium Newsletter was published in the autumn of 2007, after the $2^{\text {nd }}$ International SC Summer School took place in Ljubljana. The purpose of the SC Newsletter is to inform SC members periodically about the upcoming and past SC activities, to provide interesting information for students and young researchers in the fields covered by ISPRS. The Newsletter is published quarterly by an international team of students and young professional volunteers. The work among team members is coordinated by the Editor in Chief via e-mail and other social networks; hence, all the publishing effort is carried out by a group of students. Every member of the team is responsible for a defined part of the newsletter, such as: content design, regular rubrics, articles, interview, proof reading, etc. Each issue of the publication is made possible thanks to the involvement of approximately 1015 individuals, in addition to a number of authors for the professional articles. Along the 6 years of continuous publication, the SC Newsletter has been well received among the members. Most of the Newsletter content has its regular readers and admirers (Fig. 3), so that over $77 \%$ of them believe that the content is suitable and no longer requires further amendment.

The number of permanent team members has been increasing, especially after Summer Schools, where participants can connect with SC board members in person and discuss their expectations and obligations within the team. The newsletters are published digitally. All issues of the SC Newsletter can be found on the SC's website under the link "Materials". In addition to the digital copies, the SC Newsletter team prepared hard copy versions of the Newsletter which were distributed among participants of events. Issues are printed and distributed for all major ISPRS events, including SC Summer Schools, ISPRS Congress, and the 100th year anniversary of ISPRS with support from ISPRS, member academic organizations and funds generated with the carefully selected advertisements.

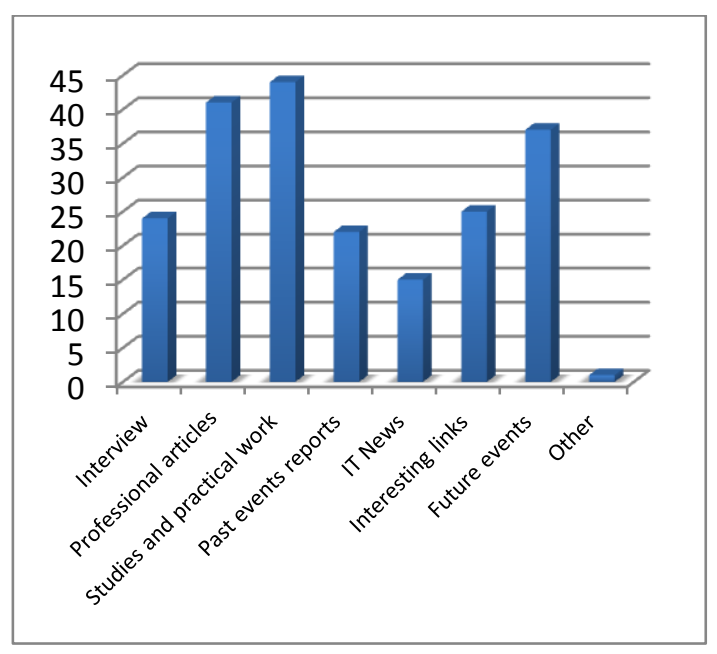

Figure 3. Graph showing the respondents' answers to the question on which part of the SC Newsletter is the most interesting for them.

Gregor Stavbor, who has carried the important role of Editor in Chief for the past years, expresses the importance of the newsletter: "The SC Newsletter is a great opportunity for students and young professionals for publishing articles about their work and research as well as to be informed about the SC's activities, job and scholarship opportunities, upcoming SC related events and other interesting information".

\subsubsection{Web Activity of the Student Consortium}

Since the very early days of the organization, communication with different individuals from different parts of the world has been a key issue. Several ideas and efforts have been discussed, and many applications were used in the early days. One of the main decisions was to establish e-mail groups, through which $\mathrm{SC}$ members could receive general announcements. Later on, to provide a networking tool, Yahoo! Groups were established for 
the members of International Summer Schools. Between 2004 and 2008, more than 7 groups were established to provide communication between active members, local organizers and participants of each event (Kivilcim, 2008). Although, this was a good step to provide the first communication means, the solution was based on general web-groups and it did not provide the desired flexibility. In addition, in order to promote the SC in www and reaching individuals from all around the world and connecting them with each other, providing more information on SC activities, and serving the members' needs with technical data and social media, a self-standing website seemed as the ideal solution. Considering these requirements, a website was designed by volunteers just before the ISPRS Congress in 2008. It has continuously updated and developed over the new term, based on the experiences of previous years. One of the fundamental components of the web utilities was the module structure shown in figure 4 (Kivilcim et al, 2010b). The five models: message boards, events, members, materials and gallery, were programmed so that dynamic pages are used with respect to the determined categories and user privileges. The website also offered a personal page for all members where they can inform of their scientific and social skills and display their resume.

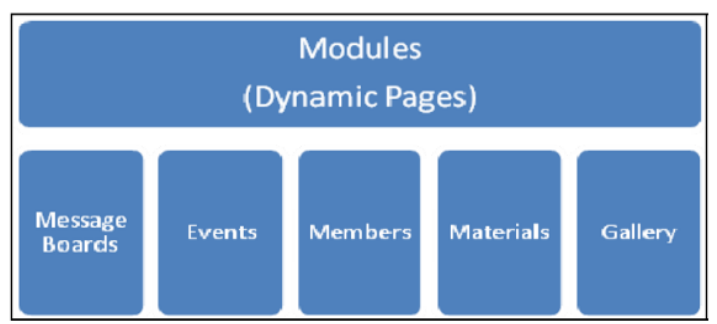

Figure 4. Web page module structure.

The website received thousands of hits per month worldwide. The distribution of the registered member regions and numbers has changed along the years 2008-2012 as seen in Figure 5. For the first time in 2011, the number of registered members from Asia raised to the first rank among the other regions. In addition to this, the Africa Region moved up to $3^{\text {rd }}$. rank, despite the fact that SC was not able to organize an event in the region due to lack of network infrastructure and political changes during the recent years.

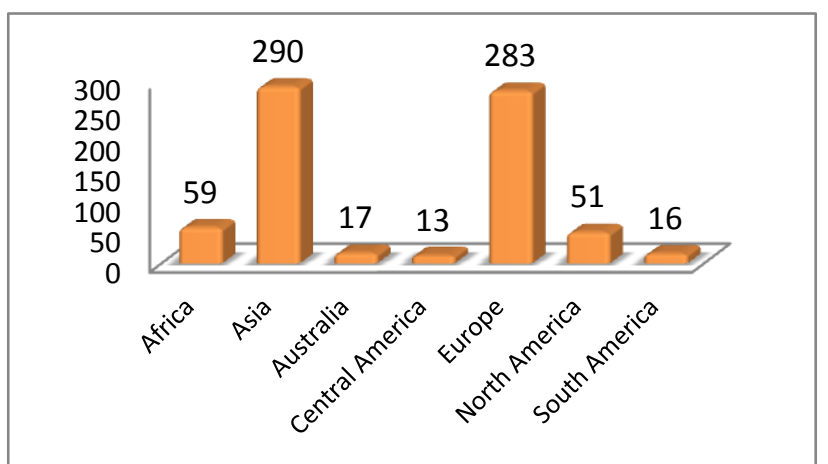

Figure 5. Regional distribution of the current members of the ISPRS Student Consortium.

In addition to the website, a Facebook group was launched in 2011 to meet the social online connection needs. The Facebook group has significantly developed in the last year and incorporates approximately 350 members.
A section of the questionnaire was devoted to learn the usefulness of the SC website and the information presented in it to our members. It was interesting to learn that $46 \%$ of the respondents visit the website regularly (from more than once a week to at least once a month); another $42 \%$ of respondents visit the website only when they receive interesting announcements while $12 \%$ rarely visit the website. This highlights the importance of e-mail notifications for many of our members and it reassures us we should maintain our efforts in this area. We were glad to learn that $50 \%$ of our respondents find the information on the SC's website interesting and useful; another $38 \%$ of respondents partially agreed with this statement while only 1 respondent disagreed with this statement.

Finally, we inquired our members about their awareness of the multiple resources other than the SC website, through which the SC shares information. We were surprised to learn that $36 \%$ of the respondents were not aware of the SC Newsletter and similarly, $36 \%$ of respondents were not aware of the SC's Facebook page. This might be explained by the high number of respondents that are relatively new to the $\mathrm{SC}$, but it encourages us nonetheless to increase our efforts in advertising all resource offered by the SC.

\subsubsection{The Student Consortium network: Regional coordination}

Soon after the creation of the formal structure of the SC, a number of regional coordinators were selected from regions all over the globe. The current SC regions that have active coordinators include: Europe, Asia, North America, Central America and Australia. This network of regional coordinators has allowed translating and focusing the efforts of the SC to each of the regions. Regional coordinators develop their mission through a variety of efforts: from aiding and facilitating the organization of events in their region, to distributing and presenting SC information at any events they may attend. Some of the greater challenges of regional coordinators involve attending to the specific needs of their region, such as language constraints for accessing information or identifying gaps in the expertise and technology available in the region relative to other regions.

Here we share the personal view of one of our regional coordinators, Elena Lobo, on the SC and her role as a regional coordinator: "In my personal experience, ISPRS has been the source of an incredibly diverse pool of resources that have played a major role in the successful development of my career. One of the unique opportunities that ISPRS has provided me with was the chance to become the Student Consortium regional coordinator for Central America and the Caribbean in April 2008. During the last four years, the role as a regional coordinator has been both extremely enjoyable and challenging. For me, contributing to the SC as a regional coordinator has involved trying to balance the enthusiasm and willingness to increase the role and awareness of ISPRS in my region with an effort to optimize available resources both on a personal and institutional front. My conclusion so far form this experience is that, through the great efforts from all ISPRS members and collaborators, it is possible to accomplish a lot, even with limited resources. There are still many opportunities to improve and expand ISPRS' reach, but I think the outcomes so far are very encouraging".

SC Asia Coordinator Kyaw sann Oo from Japan reports: "We recruit members by distributing member applications, on the other hand, we announce that SC is accepting online member 
application through SC's website with free of charge. The statistics has shown that website visiting numbers peak at the periods of regional event organizations. We noticed that colorful SC newsletters are attracting the conference participants. Interviews of well known experts and seniors show their view and experiences to youth. Our recruitments are successful."

\subsection{Events organized and participated by the Student Consortium}

Starting on 2008, the ISPRS Student Consortium has both participated in and organized several events. These could be categorized as: events organized under major ISPRS activities, self-organized Student Consortium events, or contributions to other international and regional events. At all activities, information on the SC and ISPRS were presented. Furthermore, at some of the ISPRS Symposia, specific technical sessions dedicated to the Student Consortium were held. Among all the events mentioned above, the Student Consortium International Summer Schools with ISPRS WG VI/5 are the main events, where extraordinary opportunities for learning, networking and socializing take place. In the next section, past events, based on the contribution of SC are explained.

\subsubsection{Participation of the Student Consortium and Promotional Activities in the Regions}

Starting in 2009, SC promotional activities took place in various parts of the world. Printed materials; posters and leaflets were distributed to the events. Also, an official presentation was shown to the participants of the selected events. Student Consortium members participated in many events in 2009, some of which include: a Satellite- based Photogrammetry Workshop (Habana), XXIII International Geodetic Students Meeting (Switzerland), Canadian students GEOIDE event (Vancouver, Canada), Archaeology and Cultural Heritage SS. (Trento, Italy) and the Annual Geomatics Week (Venezuela). In addition to these activities, two-day events at 2009 Asian Conference on Remote Sensing (ACRS) Beijing were organized with the SC Asian Regional Coordinator and volunteers. The events combined technical and social events for the participants (Kivilcim 2009).

In the year 2010, a great number of SC activities took place. These started with the ISPRS Symposia-related activities. The SC found opportunities and support from other Technical Commissions and Working Groups. Hence, during the ISPRS Mid-Term Symposia in 2010, several SC-oriented activities were held in different commission meetings. Then, the ISPRS Centenary Celebrations took place in Vienna, Austria, where the organization was born. The centenary celebration comprised a number of events, including a business meeting and extraordinary General Assembly. In the Centenary Celebrations, the next generation was not forgotten and several SC activities took place. Among the other activities, the Student Consortium was also involved as a member of three-jury members for a first-time award in memory of Karl Kraus. The Student Consortium Chair was and will continue to be one of the permanent members for the next award juries in all Congress terms. Additional SC promotion was carried out during SilviLaser 2010 (Freiburg, Germany).

ISPRS Technical Commission IV \& AutoCarto in conjunction with ASPRS/CaGIS 2010 Fall Specialty Conference (Orlando, USA) was an important event for SC. The SC Board Chair and Co-Chair were invited to the meeting in order observe the activities and opportunities presented by ASPRS to the students. As selected members of the ASPRS Student Assistant committee, SC members assisted with the organization of the event and in compensation were able to enjoy the event with support for accommodation and registration. In addition, the SC members attended to workshops, presented their research work and gave a speech at one of the General Sessions. During the meeting of the ISPRS and ISPRS youth councils, the need for communication, information sharing and networking between the two societies were concluded with a written agreement for collaboration.

The ISPRS TC V Midterm Symposium held in New Castle upon Tyne, UK included a special session dedicated to Young Authors. Furthermore, the technical session abstracts were reviewed by topic related-SC Board member and SC UK representative Matthias Kunz. The meeting was also chaired by a SC representative and social activities were also organized during the event.

The Student Consortium participated at the ISPRS Technical Commission VI (ITC, Netherlands) with two papers where a special session for the Student Consortium was held. Since SC activities are mainly in the TCVI domain, the meeting was also vital to evaluate the situation of the SC at the mid- term.

In 2011, the SC was also involved in multiple events, where SC promotional activities were developed. Some of these events included: ISRSE 34 (Sydney, Australia), ASPRS 2011 Annual Conference (Milwaukee, USA), Latinamerica ESRI User Conference (San Jose, Costa Rica), $1^{\text {st }}$ EARSeL SIG Forestry workshop (Prague, Czech Republic), ASPRS/ Pecora Fall Special Conference (Virginia, USA) and the 32nd Asian Conference on Remote Sensing (Taipei, Taiwan). In addition to these activities, the ACRS 2011 had three student events during the conference such as "WEBCON", "Student Session", and "Student Night". This meeting also played an important role for the Asia Region. During the meeting, the organization of Asian Student Chapter under ACRS was established.

\subsubsection{Summer Schools}

The Student Consortium (SC), together with the WG VI/5: "Promotion of the Profession to Young People", organized four international Summers Schools between 2009 and 2011. More than 200 students and young professionals participated in them. These events were always focused on an advanced level for lectures, reduced costs of participation and on a large number of social events.

The advanced level for lectures was provided and warranted by the contribution of many ISPRS academicians and professionals. Their contributions to Summer Schools were provided with no cost, other than the reimbursement of their transportation costs. This is has been a great contribution by current professionals for the development of the youth. More than $86 \%$ summer school participants, who completed the questionnaire, came up with new ideas on the Summer School that would be useful and interesting for the further development of their careers and even their jobs. Costs of participation were minimized, which all expenses related to the activity covered with small registration fees. These reduced prices make it possible for many students from developing countries to participate.

Giving the students the opportunity of networking was one of the most important reasons for organizing Summer Schools. 
This is confirmed by the results of our member survey, showing that for $25 \%$ of participants this was the most important reason to take part in the event, after "the interesting research topic" with $36 \%$ (Fig. 6). For $64 \%$ of the survey respondents, Summer Schools provided a chance to start international collaborations (Fig. 7)

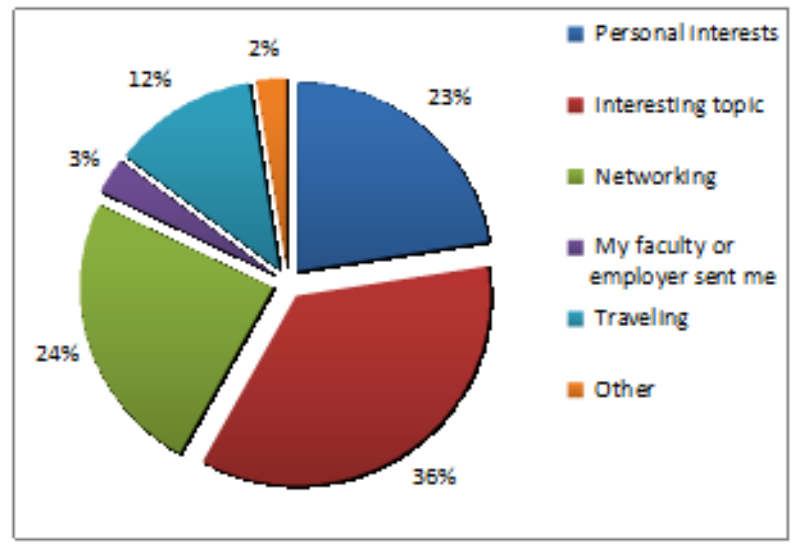

Figure 6. Graph showing the survey respondents' answer to the question: "what was your primary goal when you decided to attend the SC Summer School?"

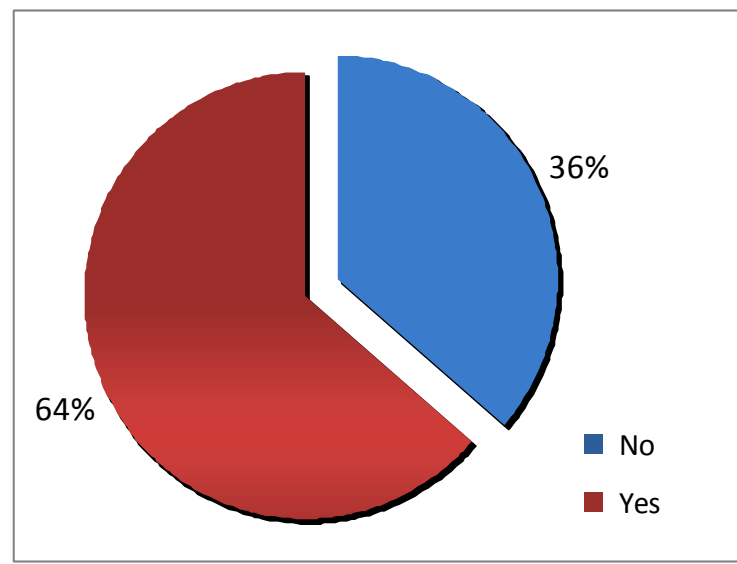

Figure7. Graph showing SC members responses to the question on whether they stayed in contact with participants and other people after the Summer School had ended

The ISPRS SC member survey showed that more than $50 \%$ of Summer School participants learned about it through the SC website and Newsletter. More than $90 \%$ of students were satisfied with their participation in a Summer School (answers: tight $8 \%$, good $56 \%$, just right $27 \%$ ); only $4 \%$ of summer school participants who completed the questionnaire were dissatisfied with them. $82 \%$ of previous Summer School participant would not change their structure. These are very encouraging results when taking into account the different nationalities and range of knowledge and skills of the participants.

General feedback of ISPRS Summer Schools is very positive. This has been shown through e-mails received by regional organizers from participants. Below we show some of the emails sent by participants of the $4^{\text {th }}$ ISPRS Summer School in Warsaw (Stereńczak and Będkowski 2009):

\section{$1^{\text {st }}$ Opinion:}

Just a few words to thank you for giving me the opportunity to participate in this summer school!!!
Many congratulations to you personally, to the students that worked as volunteers and to everyone that contributed in order this summer school become a reality.

For me it was a great experience, and to be honest I didn't expect to see such an organization!!! Even if some of the participants didn't found some of the lectures advanced enough, for me it was no problem at all...the program of the summer school was published months ago before registering...If one see the title "Land Cover Classification" what he or she would expect to listen to? For me also there were stuff that I already know (I have done MSc in Photogrammetry - Remote Sensing and now I am on the PhD) but the fact that I have listened at least to few things for the first time and I had the chance to interact with many fellow researches, students and academic staff from around the world......this was far more my expectations! I wouldn't missed that for nothing!!!!!!

To make it short

You guys, were absolutely GREAT!!!!!!!!

THANK YOU!!!

\section{$2^{\text {nd }}$ Opinion:}

I've arrived at home just a couple of hours ago.

Thank you and all other organizers once again for the great experience. See you (as) soon (as possible)! :)

\section{$3^{\text {rd }}$ Opinion:}

I just want to thank you for the great event we had last week. Congratulations for the excellent and outstanding organization, you (and your "crew") really did a great job!

I think the program was well-balanced between theory and practice and most of the lectures were really interesting for me. Since you can never satisfy everybody with every lecture, this is a perfect result ;-)

You made us feel comfortable, you organized exciting social events and over all you gave us a great platform to get in contact with each other. We really felt in good hands and I will always remember the great hospitality we experienced in Warsaw.

In any case I will recommend ISPRS Summer School to other students and hope that the next host can keep up with you.

This is a great example of how summer schools are important to young people and of why they they are necessary and they should be continued.

The $4^{\text {th }}$ ISPRS Student Consortium Summer School was held between 13-18 July 2009 with the title "Natural Environment Management, Monitoring and Conservation" in Warsaw, Poland. 57 international participants from 15 countries and 30 local students attended the event (Fig.8). (Sterenczak and Bedkowski, 2009)

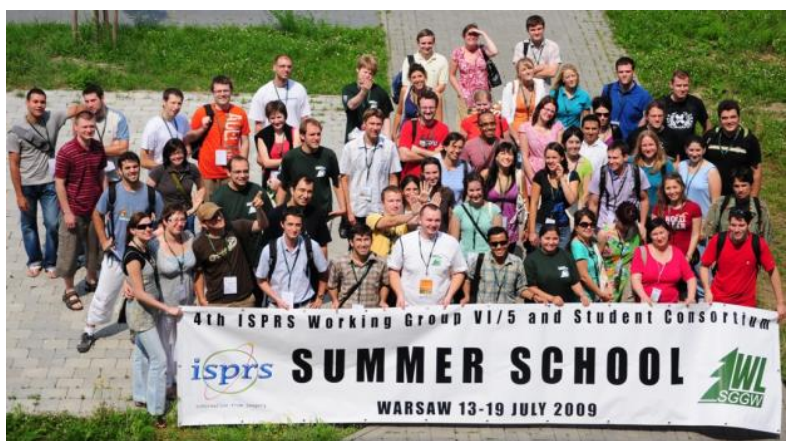

Figure 8. $4^{\text {th }}$ Summer School Participants in Warsaw, 2009 
The $5^{\text {th }}$ Summer School was held in Southeast Asia, in the capital city of Vietnam, Hanoi, where 54 participants gathered from the $6^{\text {th }}$ to the $10^{\text {th }}$ of November 2010 (Fig. 9). The Summer School took place immediately after the $31^{\text {st }}$ Asian Conference on Remote Sensing (ACRS) 2010, which combined the strengths of many of the top Asian remote sensing scientists. The main theme of the summer school was "Advanced Remote Sensing for Mapping, Monitoring and Management of the Environment" and was a puzzle of four day lectures supported by practical exercises and an all-day trip along the Red River to visit temples and villages. Lectures went in-depth into the themes of microwave remote sensing, change detection of land use/land cover, natural hazards and topographic mapping from high-resolution satellite sensors.

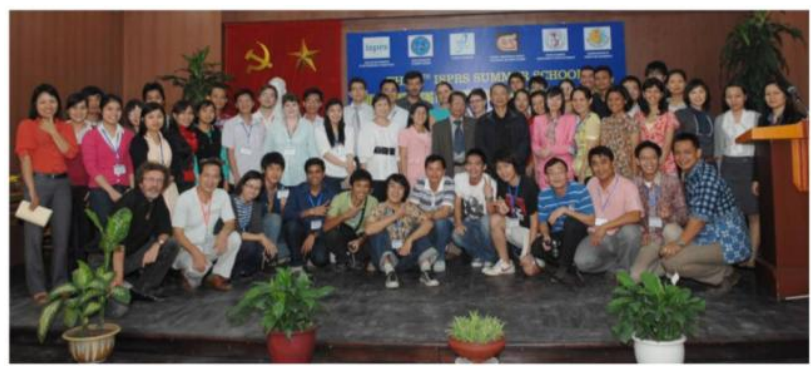

Figure 9. Participants of the Summer School held after ACRS 2010

The 6th ISPRS WG VI/5 and SC Summer School "Advanced LiDAR Processing and Applications" was held at Fayetteville State University from July $30^{\text {th }}$ to August $6^{\text {th }}, 2011$ (Fig. 10). Fifty-three participants from 20 countries and 20 from the U.S. attended this student-focused conference. This was the first ISPRS SC Summer School held in the United States. Such ISPRS Summer Schools promote spatial sciences by providing an intensive week of training and other educational activities for students and young researchers in geospatial fields. In addition to learning theoretical concepts in lectures, the aim of summer schools is to demonstrate to its participants the practical and laboratory aspects of the science. Equally important is the social context of such meetings as they facilitate the exchange of ideas and provide a base for further international cooperation. During the summer school, the students travelled to Myrtle Beach, South Carolina for a day trip. It was a welcome break for everyone to leave the lecture hall behind and interact on a more personal level. The week-long event was packed with 7 lectures and 3 laboratory practical sessions by internationally recognized academicians and experts who came from Europe, Canada, and the United States. The students also had the opportunity to interact with industry specialists (Bourland, 2011)

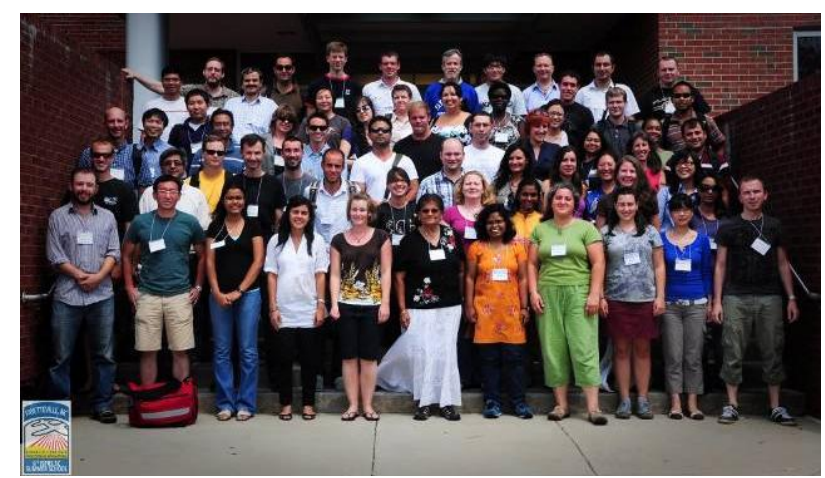

Figure 10. Group picture from Fayetteville Summer School.
The $7^{\text {th }}$ Summer School was held at the National Central University (NCU), Jhongli, Taoyuan, Taiwan Oct. 8-12, 2011. The theme of the $7^{\text {th }}$ Summer School was "Spatial Information Sciences for Environmental Monitoring", with presentations by seven international professors and one post-doctoral student. The number of participants reached 48 who came from 16 different countries (Fig. 11).

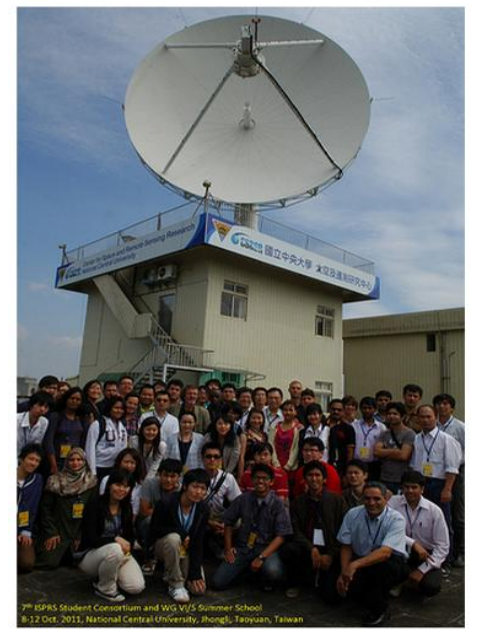

Figure 11. Groups picture from Taoyuan Summer School

Two student events were held in the summer school, including a "Student Paper Session" and a "Social Event". The local organizers encouraged participants to introduce their research activities and compete for awards for best paper and best presentation. Besides lectures, the local organizers also held two social events to welcome all participants. These two events, a visit to a night market and a welcome party, let them enjoy Taiwanese culture and share their life experience (Kanjir 2012).

\subsubsection{International and Regional Symposia/Conference}

One of the SC activities that are showing great promise are the Conferences. On July $18^{\text {th }} 2009$, just after the $4^{\text {th }}$ ISPRS SC Summer School, the $1^{\text {st }}$ ISPRS Student Conference on "Photogrammetry and Remote Sensing in Natural Environment Management and Monitoring" took place (Fig. 12). The main purpose of this conference was to acquire experience in presenting scientific work by young researchers. There were more than 30 abstracts sent for this event. There were 4 sessions:

- Land use / land cover classification

- Change detection

- Data processing techniques

- GIS and LIDAR applications

The level of the presentations was very advanced and brought about a lot of very interesting discussions, which continued during brakes. Organizers prepared awards, which were given to the best students for presentation, poster and paper categories.

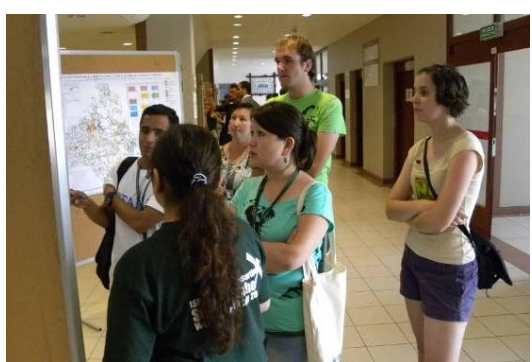

Figure 12. Poster Session during the $1^{\text {st }}$ ISPRS SC Conference 


\section{EVALUATING THE STUDENT CONSORTIUM}

\subsection{Analysing the Network}

The survey focused on many issues but also on how the members got acquainted with the organization, their general perception of international connections for professional and personal life.

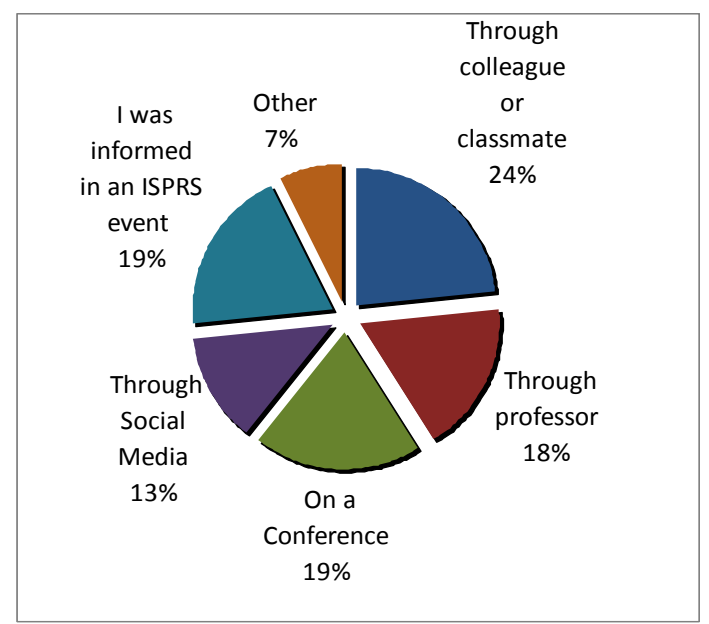

Figure 13. Representation of the results of first question on how members are first acquainted with the SC.

Upon analyzing the results of the survey, we understand that the knowledge on the existence of the organization originates from different sources (Fig. 13): almost one fourth of the members who completed the survey heard about the Student Consortium through their colleagues or classmates; less than $20 \%$ were told by a member of the teaching staff; the same percentage heard about it at professional events (conferences) and the same amount of people got informed in an ISPRS related event; a minority of respondents of our survey (only 13\%) joined organization after they discovered it through some social media (most probably SC official website and Facebook profile). As we can see from the results and also from our practical experiences, we can conclude that a significant amount of members are gained by having contact in person.

Another interesting outcome of the survey was to learn that while $35 \%$ of respondents have been SC members for over two years, $19 \%$ have only members for over a year and $47 \%$ joined $\mathrm{SC}$ over the last year. These results might indicate that the more recent strategies of the SC are having a great success in attracting new members.

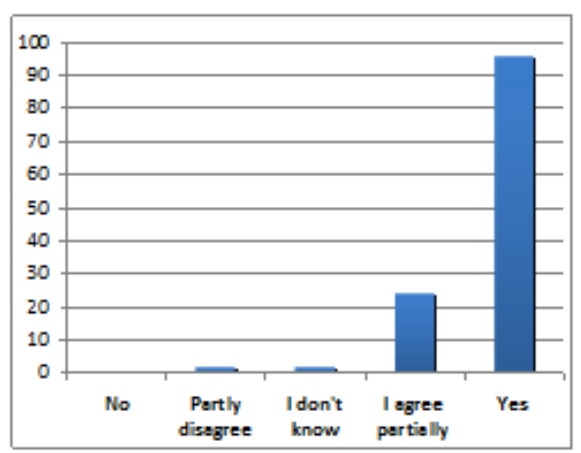

Figure 14. Graph showing the survey respondents answer to the question on whether integration of students and young researchers is important for developing an individual's career.
We were not surprised to learn that 97 percent of the survey respondents believe community involvement is either very important or somewhat important for developing an individual's career (Fig. 14). It is almost what Thomas Jefferson called a "self-evident truth". More unexpected, was to learn that apparently few people partially disagree with seeing integration of an individual into communities as valuable.

We are confident that the findings from the survey will be helpful to the Student Consortium and the community in terms of the next major priorities and future activities and organization. It is evident from these findings that a significant effort is required to provide effective, easy-to-find information on how to get started with contributing to the SC community. However, help from other community members is needed to keep the momentum going.

\section{THE ROAD AHEAD FOR THE STUDENT CONSORTIUM}

\subsection{Positive and Negative Impacts}

The most important experience learned from the past eight years of Student Consortium activities is that the promotion for the development of the Network has to be a continuous effort. Young people are very active while they are studying, but this period passes rapidly and when they move on to their jobs, they usually give up student activities. This creates a problem in societies like ours, because members are active for a short time, concerning ISPRS activities. The rapid rotation of contributing members makes it difficult to carry out some initiatives. This causes additional problems at the national/country level where there are great challenges for integration of youth into ISPRS.

Nowadays, social media such as Facebook are replacing old and static structures of scientific networks. These types of media are attractive in various ways, which is why all sorts of institutions are using them for business and scientific activities as opposed to personal purposes. Our experience from the last year proves that the Facebook ISPRS SC group was much more active than the SC network established on our website. Nevertheless, using the network in the best possible way is the most important challenge, and without it, promoting would not be possible. In contrast, the survey results show the importance of a website to allocate necessary documents and data and more resources. Hence, the SC should consider the best ways to integrate the social media into the website.

\subsection{Expectations from Student Consortium and Society}

Several aspects could be mentioned here, focusing only on improving things, while keeping all positive aspects as they are. With the experiences gained in the years some ideas and suggestions are highlited here for the sustainability of SC.

In order to make SC a permanent aspect in ISPRS it is suggested to mention it in ISPRS Statutes and especially Bylaws. Furthermore, Regulations from Council/TCPs for facilitating participation of SC members to ISPRS events should beestablished, including student registration fees at maximum $30-50 \%$ of the regular fees, free registration for some SC board members, special attention regarding support from ISPRS Foundation.

Finances are as we all know an issue, especially at the current so-called "financial" crisis. SC cannot develop activities without 
some sort of financial support. ISPRS should permanently and steadily support SC activities and events. Sponsors, especially among the ISPRS sustaining members, should contribute to it.

Most SC members are at a Master or PhD Level and quite some of them need a publication outlet. This could be within proceedings of events or publications. For example, student oral sessions (naturally of good papers) could be a permanent part of ISPRS, large enough, events, like Symposia. Maybe ISPRS Journal and Highlights could have a section for student papers and news, respectively.

Special attention should be paid to youth in poorer countries who cannot attend most ISPRS events by regularly organizing activities in these regions.

ISPRS should encourage the ordinary members of ISPRS to develop their national organization's youth body and connect them with ISPRS Student Consortium. Likewise, students and young professionals should demand and apply to their national body for such structures.

-In the future we believe that organizing scientific competitions may be another good solution to activate local groups of networks.

The networking should be kept alive as it was aimed and succeed up to now. In addition to increase the coverage and the number of members, SC should provide more volunteer activities with possible competitions, and activities at national and local levels. In order to achieve this, the national members of the society should provide the necessary background for establishing active youth bodies. Furthermore, collaborations such as with ASPRS Student Advisory Council should continue with activities. It should be also noted that possible collaborations with other sister societies in different regions and within networks such as International Federation of Surveyors should be signed.

\section{CONCLUSION}

The Student Consortium is in preparation for the 2012 Melbourne Congress. In addition to the official activities including a full-day Youth Forum and social activities through the Congress, the SC Board will hand over the flag to the next generation.

With the motivation and support from the Society, SC volunteers continue to produce solutions to meet their own needs. In this way, we not only develop our skills and enjoy working in international team but also contribute to the future of the Society. Last but not least, SC members enjoy the social activities.

ISPRS has been a pioneer organization in terms of adapting to the changes in the science and technology. During the extraordinary meeting of ISPRS centenary celebrations in Vienna 2010, the ISPRS fields were redefined in order to adapt to the global scientific and technical changes. Likewise, the Student Consortium activities have been an excellent way of promoting the society. We believe the Student Consortium will pass on the energy and synergy of the youth to future generations. We hope that past SC members will assume roles and responsibilities in the continuum and for the advancement of ISPRS.

\section{Acknowledgements}

The SC Board and members would like to express their gratitude to all volunteers and supporters from its establishment.
None of these accomplishments would have happened without the passionate scientists, experts and members who contributed to the ideas, activities and events of ISPRS SC. Without their support and efforts the SC will not exists at all including this paper. We would like to express our deepest gratitude to Dr. Emmanuel Baltsavias for offering his continued support and friendship to SC, also to ISPRS TC VI .Commission Chair Prof. Dr. Martien Moolenaar, WG VI5 Officers Dr. Nguyen Dinh Duong, Dr. Duong Dr. Anka Lisec, other Technical Commission Chairs and to Prof. Dr. M. Orhan Altan, President of ISPRS Council 2008-2012.

\section{References}

Akkoca, G., Tatli, P., Celik R. N., 2006. Organization and Future of ISPRS Student Consortium. E-learning and the next steps for education. Cho, K. (ur.), Yoshimura, M. (ur.). Proceedings of ISPRS Technical Commission VI Symposium 2006.ISSN 16821750: 198-201

Baltsavias, E., 2005. Student Activities within ISPRS, ISPRS Highlights, Vol.10, No.3, pp. 7

Bourland, D., 2011, The $6^{\text {th }}$ SC ISPRS Summer School, ISPRS SC Newsletter October 2011, http://www.isprs-sc.org/material/isprs_sc_vol5_no3.pdf

Kanjir, U., 2011, Report on the 5th ISPRS Student Consortium and WG VI/5 Summer School. 6-10 November 2010, Hanoi, Vietnam,

http://www.isprs.org/news/newsletter/03-Apr2011/52_Report_on_the_5th_ISPRS_Student_Consortium _and_WG_VI5_Summer\%20School.pdf

Kivilcim, C. O., 2008.Proceedings of the ISPRS Student Consortium: Participation of the youth for a sustainable society. Proceedings of XXIst ISPRS Congress Beijing, 2008

Kivilcim, C. O., 2009, ISPRS Highlights No.9 April 2010 http://www.isprshighlights.org/nieuws/item.php?nieuws_i $\mathrm{d}=158$

Kivilcim, C. O., Sterenczak, K., Kanjir, U., Sengul, A., Stavbar, G., Pakdil, M. E., Lobo, E. and Oo, K. S., 2010, ISPRS Student Consortium Mid-Terrm Status Report (20082010) Proceedings of ISPRS TC VI Mid-Term Symposium, ITC The Netherlands, 2010

Kivilcim, C. O., Ercan, P. M. and Sengül, A., 2010b. Role of Internet as a communication platform and ISPRS Student Consortium Web Site, Proceedings of ISPRS TC VI MidTerm Symposium, ITC The Netherlands, 2010

Kosmatin Fras M., Lisec A., 2008. Promotion Activities of the profession to students in period 2004-2008 and future prisoects. Proceeedings of XXIst ISPRS Congress Beijing 2008

Molenaar, M., 2011, ISPRS TC VI Report, 2011, http://www.isprs.org/news/newsletter/2012_01/15_TC_VI _Annual_Report_2011.pdf

Stereńczak, K. and Będkowski, K. 2009. 4th ISPRS WG VI/5 and Student Consortium Summer School. ISPRS Highlights 9, 3. ISSN 0717-2931 